\title{
Research on the Willingness to Use Shared Logistics Facilities Under the Background of Sharing Economy:Based on the Model of Moderating Effects
}

\author{
Jie Tan \\ School of Management, Shanghai University, 99 Shang Da Road, Shanghai 200444, China
}

\begin{abstract}
In the academia, there were so many papers about behavior intentions in the traditional business model, but so little attentions were paid to the factors which influenced smart express cabinet behavior intentions under the background of sharing economy. The relationships between smart express cabinet perceived factors, green value and behavioral intentions were revealed. Through literature review, the perceived factors for smart express cabinets were measured using functional value, emotional value, price perceived value and service quality perceived value. A structural equation model (SEM) was then developed to describe those correlations and effects. The results show that functional value, emotional value and price perceived value have direct positive impacts on behavioral intentions. In addition, green value adjusts the relationship between functional value, price perceived value and behavioral intentions. Therefore, attaching importance to green value and improving service from functional value, emotional value, price perceived value in logistics industry are essential ways to increase behavioral intentions.
\end{abstract} Keywords: green value, sharing economy, customer perception, behavioral intentions.

DOI: $10.7176 / \mathrm{EJBM} / 11-17-05$

Publication date:June $30^{\text {th }} 2019$

\section{Introduction}

According to the "Statistical Bulletin on the Development of the Postal Industry in 2018" issued by the State Post Bureau, the volume of express delivery exceeded 50 billion in 2018 . While the express delivery industry is developing rapidly, it has also exposed a series of problems. In the traditional logistics distribution process, the distribution environment is messy and the violent sorting is becoming more and more obvious. The quality of logistics terminal distribution is being questioned more and more, and the "last mile" problem of e-commerce logistics is also more and more prominent. At the same time, shared logistics emerges as the times require. Shared logistics facilities such as intelligent express cabinets emerges and become a reliable force to facilitate people's social life. Therefore, it is particularly important to explore the factors affecting the willingness to use end-sharing logistics facilities.

In the theory of Behavioral Intelligence (BI), scholars have done a lot of research. For different types of goods, the performance of behavioral intention is different. This paper takes the intelligent express cabinet as the research object to study the customer's use intention. Fishbein and Manfredo (Fishbein \& Manfredo 1992) point out that understanding customers' propensity to take certain actions can help predict future specific actions. Dong Dahai and Jin Yufang (Dong Dahai \& Jin Yufang 2003) pointed out that consumers'behavioral willingness mainly includes three categories: repurchase tendency, word of mouth and premium purchase. Subsequently, scholars extended the study to the factors affecting behavioral willingness. There are many factors affecting behavioral willingness. Perception factors have been tested to have an impact on behavioral willingness (Chang and Wildt, 1994; Chen, 2008; Chen Jie and Wang Fanghua, 2012; Eggert and Ulaga, 2013; Xiuyan, 2014; Shi Yiran, 2017; Cui Dengfeng and Li Shumei, 2018). In the field of logistics, there are many articles on behavioral willingness. Chen Zhenghui and others (Chen Zhenghui, 2010) believe that customer's perceived value of express service affects customer's reuse willingness. Zheng Chundong et al. (Zheng Chundong et al., 2012) believed that the remedy of express delivery service errors would have a significant effect on users'willingness to buy again. But all of these studies are about the influence factors of express service industry under the background of traditional business model. What are the perceptive factors that affect the willingness to use of new shared logistics service facilities such as intelligent express cabinet under the shared economy model? At present, few scholars have studied it. Through literature review, this paper divides the perception factors affecting the use intention of intelligent express cabinet into four aspects: Functional Value (FV), Emotional Value (EV), Price Perceived Value (PPV) and Service Quality (SQ).

In addition, the shared economy is different from the traditional economic model in that it takes into account people's spiritual pursuit of environmental protection, thus promoting the development of ecological economy (Dong Chenghui, 2016). Green Value (GV) is the result of the development of ecological economy. Therefore, in the development of shared economy, green value is an important factor that has to be considered. Regarding green value, Yang Xiaoyan and Zhou Yinjin (Yang Xiaoyan and Zhou Yinjin, 2006) pointed out that green value is a new dimension of perceived value. Chavez et al. (Chavez et al., 2016) pointed out that paying attention to consumer 
demand and building a green value chain would help improve consumer satisfaction. The above studies have emphasized the positive role of green value, but few have studied the regulatory role of green value, and less have studied the impact of shared logistics facility perception factors on willingness to use as a regulatory variable. In fact, with the enhancement of people's awareness of environmental protection, when consumers perceive higher green value in purchasing products or receiving services, they are more likely to enhance their preference for the products or services, and the impact of perceived value on consumers'behavior will be greater.

Shared logistics facilities are exerting a great influence on social life. The government formally implemented the Provisional Regulations on Express Service on May 1, 2018, which encourages many enterprises engaged in express business to share terminal service facilities. Therefore, this paper takes the shared intelligent express cabinet as the research object to explore the factors affecting customer's willingness to use. This paper finds that functional value, emotional value and price perception have a direct positive impact on customer's willingness to use. In addition, green value adjusts the impact of functional value and price perception on customers'willingness to use. The conclusion of this paper clarifies the role of green value in the era of shared economy, deepens the research of customer perception theory in the context of shared economy, and provides suggestions and suggestions for logistics enterprises to better serve customers and solve the "last mile" problem under the background of shared economy.

\section{Research Hypothesis}

\subsection{Perception Factors and Use Intention}

The effects of functional value, emotional value and price perception on behavioral willingness have been widely confirmed by theory and empirical evidence (Chang and Wildt, 1994; Chen, 2008; Chen Jie and Wang Fanghua, 2012; Eggert and Ulaga, 2013; Xiuyan, 2014; Shi Yiran, 2017; Cui Dengfeng and Li Shumei, 2018). In the field of logistics, Pang Zhonghua (Pang Zhonghua, 2018) takes the intelligent express cabinet as the research object, and points out that service quality has an impact on consumers'willingness to use it. Based on the above literature, after fully considering the characteristics of shared intelligent express cabinet, four perception factors are extracted: functional value, emotional value, price perception and service quality perception. In choosing and purchasing goods, customers first pursue the quality and performance of products, that is, functional value (Yang Xiaoyan and Zhou Yijin, 2006). Liu Zhenhua (Liu Zhenhua, 2017) pointed out that the functional value of complementary products was positively correlated with purchase intention. Cui Dengfeng et al. (Cui Dengfeng and Li Shumei, 2018) found that the functional value of characteristic agricultural products had a significant positive impact on behavioral intention.In fact, logistics enterprises share information so that consumers can grasp more information, and consumers are increasingly demanding the function of products. Especially at present, privacy leaks occur frequently, and the public pays more attention to the protection of their privacy. Shared logistics facilities such as intelligent express cabinets have the function of protecting personal privacy and can attract customers to choose to use them. Therefore, the following hypotheses are proposed:

H1a: Customers'perception of the functional value of the intelligent express cabinet will positively affect their willingness to use it.

Value is the corresponding utility per unit (Miles, 1962). Emotional value refers to the emotional utility that customers get in the process of purchasing products or receiving services, and more refers to emotional experience such as pleasure. Liu Zhenhua (Liu Zhenhua, 2017) pointed out that perceived emotional value positively affected the willingness to buy complements. Wang Dahai and others (Wang Dahai, 2018) believe that emotional value can positively affect customers'repeated purchasing intention of green products. Shared economy can improve increasingly closed interpersonal relationships and class barriers (Ruan Xiaodong, 2015). In fact, the sharing of goods and information brought about by the sharing economy can create a more harmonious atmosphere, narrow the gap between classes, promote the development of interpersonal relationships, and then make people get a pleasant physical and mental experience. For the intelligent express cabinet placed in the school, because of its shared use characteristics, it has created an invisible communication platform. Between teachers and students, students may meet and communicate with each other in the same smart express cabinet to get a better emotional experience. Therefore, the following hypotheses are proposed:

H1b: Customers'perception of emotional value of smart express cabinets will positively affect their willingness to use them.

Chen Jie and Wang Fanghua (Chen Jie and Wang Fanghua, 2012) empirically studied four categories of goods, namely fast moving consumer goods, durable consumer goods, luxury goods and services, and concluded that price value has an impact on purchase intention through consumer attitudes. At present, there is no perfect management mechanism for pricing in China's service industry, so the impact of price perception on customer behavior intention is still significant (Kuo et al., 2009). As a new shared logistics service facility, intelligent express cabinet has no uniform charging standard at present, and even most of them provide services free of charge, so many people will choose to use it because of its affordability. Therefore, the following hypotheses are proposed: H1c: Customers'price perception of smart express cabinets will positively affect their willingness to use them. 
Duan Bing (Duan Bing et al., 2013) believes that customer satisfaction comes from service quality perception. Customer satisfaction has an impact on behavioral intention. Pang Zhonghua (Pang Zhonghua, 2018) takes the intelligent express cabinet as the research object, and points out that service quality has an impact on consumers'willingness to use it.Sharing economy is a service-oriented economy. Sharing the information of intelligent express cabinet enables consumers to grasp more information and to compare and choose preferred services more easily. As a result, the perception of service quality is enhanced, and the probability of choosing to use the shared intelligent express cabinet is also increased. Therefore, the following hypotheses are proposed:

H1d: Customers' perception of service quality of smart express cabinet will positively affect their willingness to use it.

\subsection{The Moderating Effect of Green Value}

Green value is the overall evaluation of products after consumers perceive environmental benefits and costs (Ariffina et al., 2016). Guo Ping (Guo Ping, 2016) believes that green perceived value plays a moderating role between green trust and purchase intention. Wang Dahai and others (Wang Dahai, 2018) believe that green perceived value can positively affect the repeated purchase intention of green products.

In fact, the shared economy is a sustainable mode of green economic development. With the rapid development of the shared economy and the continuous improvement of people's living standards, the overall national environmental awareness will be enhanced, and the impact of green value on consumers'behavior will gradually increase. For consumers with strong green value perception, the perceived price-performance ratio of commodities will be higher, and when their consumption psychology of pursuing environmental protection is taken into account in time, the perception of service quality will also be enhanced. The heart will be happier and make behavioral choices. At the same time, enterprises pay attention to and strive to improve the green value, which is the expression of positive social responsibility. It is conducive to establishing a positive corporate image in the hearts of consumers, establishing corporate reputation, improving consumers'recognition of enterprises, and thus enhancing consumers' willingness to buy and use. Therefore, the following hypotheses are proposed:

$\mathrm{H} 2 \mathrm{a}$ : Green value plays a moderating role between functional value and willingness to use. The stronger the perception of green value, the greater the impact of functional value on willingness to use.

$\mathrm{H} 2 \mathrm{~b}$ : Green value plays a moderating role between emotional value and willingness to use. The stronger the perception of green value, the greater the impact of emotional value on willingness to use.

$\mathrm{H} 2 \mathrm{c}$ : Green value plays a moderating role between price perception and willingness to use. The stronger the green value perception is, the greater the impact of price perception on willingness to use.

$\mathrm{H} 2 \mathrm{~d}$ : Green value plays a moderating role between perceived service quality and willingness to use. The stronger the perceived green value is, the greater the impact of perceived service quality on willingness to use.

Fig. 1 describes the relationship between the above assumptions and constructs the theoretical research model of this paper.

Customer Perception

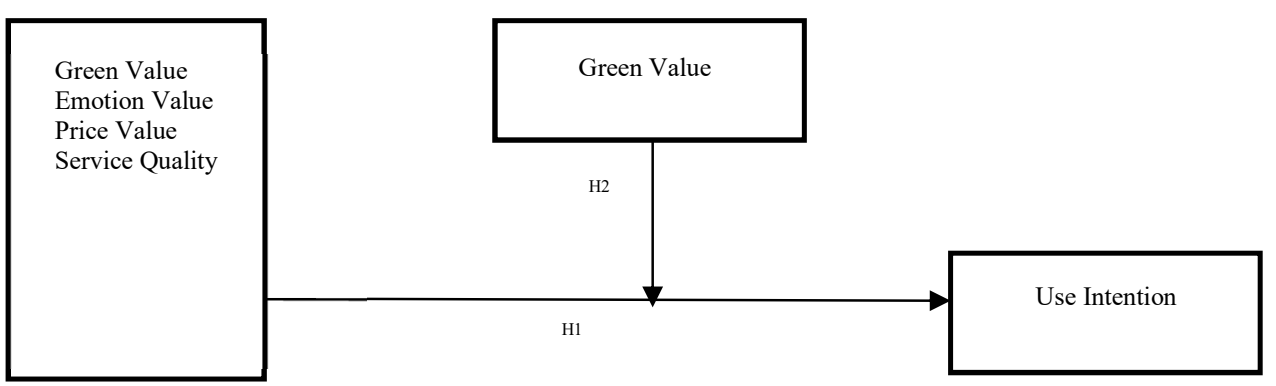

Figure 1.Research Model

\section{Research Design}

\subsection{Sample Description}

This paper adopts the method of questionnaires to conduct research. The items of the questionnaire are divided into seven points. 1 - 7 represents "very disagreement" to "very agreement" respectively. 404 questionnaires are collected. The survey results showed that the female respondents were more than the male respondents, accounting for $53.57 \%$; the age group was between 18 and 25 years old, accounting for $53.32 \%$; the majority of undergraduates were educated, accounting for $72.45 \%$; the majority of the respondents lived in Shanghai, accounting for $11.22 \%$. 


\subsection{Variable Measurement}

In order to improve the reliability and validity of the questionnaire, the measurement items in this study mainly refer to the more mature scale used by domestic and foreign scholars, and modify it according to the actual situation of the intelligent express cabinet.

Perception factors mainly refers to Sheth et al. (1991) scholars' point of view. Functional value includes two topics, including "using intelligent express cabinet is beneficial to protecting personal privacy". Emotional value includes three topics, including "feeling relaxed when using intelligent express cabinet". Price perception includes five topics, including "service pricing of intelligent express cabinet is reasonable". Four items are set for service quality perception, including "good service attitude of intelligent express cabinet managers".Green value refers to the scale developed by Yang Xiaoyan and Zhou Yinjin (Yang Xiaoyan\&Zhou Yinjin, 2006). Five items are set up, including "using intelligent express cabinet will reduce environmental pollution".Using Dodds et al. (1991) theoretical research and Jandas et al. (2002) scale of loyalty for reference, the use intention can be summarized into three items, including "I will choose and use the smart express cabinet" and so on.

\section{Analysis of Empirical Results}

This paper uses SPSS22.0 and AMOS21.0 statistical software to carry out empirical analysis of data. Firstly, the reliability and validity of the questionnaire are analyzed, and then the hypothesis test is carried out by using structural equation model method.

\subsection{Reliability and Validity Test of the Model}

This paper uses Cronbach alpha coefficient method to measure the internal consistency among items in the questionnaire. After adjustment, the Cronbach alpha coefficient of the total scale is 0.950 , and the Cronbach alpha coefficient of each latent variable is greater than 0.8. Among them, the functional value is 0.801 ; the emotional value is 0.862 ; the price perception is 0.892 ; the service quality perception is 0.881 ; and the willingness to use is 0.820 . The reliability of the results of the questionnaire is relatively high.

In addition, the validity of the observed variables is analyzed by constructing structural equation model. The normalized coefficients of the observed variables are obtained by constructing the structural equation model to measure the relative variation level of the variables. In order to verify the convergence validity of the sample, the AVE of the latent variable is calculated by using the normalized coefficients of the observed variables. AVE reflects how much of the variance explained by each latent variable comes from all the topics in the latent variable. The AVE value in Table 1 is more than 0.5, which indicates that each latent variable has better convergence validity.

Table 1. Reliability and Convergence Validity of Perceived Factors and Use Intention

\begin{tabular}{ccccc}
\hline Latent variables & Observed variables & Cronbach & Standardization coefficient & AVE \\
\hline FV & a1 & 0.801 & 0.83 & 0.67 \\
a2 & a3 & & 0.81 & 0.67 \\
a4 & a5 & 0.862 & 0.79 & 0.86 \\
a6 & a7 & & 0.81 & 0.65 \\
PPV & a8 & 0.892 & 0.80 & \\
& a9 & & 0.78 & 0.80 \\
a10 & & 0.84 & 0.65 \\
a11 & a12 & & 0.81 & \\
& a13 & 0.881 & 0.85 & 0.83 \\
\\
& a14 & & 0.72 & 0.81 \\
\end{tabular}

\subsection{Goodness of Fit Test of Confirmatory Factor Analysis Model}

Table 2 is the overall goodness-of-fit result of the model after confirmatory factor analysis, and each index value meets the requirements. The ratio of chi-square value to degree of freedom is less than 3 . Comparing fitting index CFI, incremental fitting index IFI Delta2, non-standard fitting index TLI Rho and standard fitting index NFI are all greater than the critical value 0.9 . The RMSEA of approximate root mean square is also less than the critical value 0.08 , RMR of residual root mean square is less than 0.05 , which further shows that the fitting degree of the model and data is good 
Table 2. Goodness of Fit Test of Confirmatory Factor Analysis Model

\begin{tabular}{cccccccc}
\hline$\chi 2$ & $\chi 2 / D F$ & CFI & IFI Delta2 & TLI rho2 & NFI & RMSEA & RMR \\
\hline $\mathbf{1 8 0 . 6 3 3}$ & 2.030 & 0.978 & 0.978 & 0.970 & 0.958 & 0.051 & 0.039 \\
\hline
\end{tabular}

\subsection{Hypothesis Testing}

For the research hypotheses mentioned above, the results of structural equation model analysis are shown in Table 3. The model assumes that the relationship is embodied by the normalized path coefficient, and the significance level is tested by the P value. If the $p$ value is less than 0.01 , the path coefficient is very significant. If the $p$ value is less than 0.05 , the path coefficient is significant. From Table 3, we can see that functional value has a significant impact on use intention, which is consistent with the original hypothesis H1a. Emotional value has a positive and significant impact on willingness to use, which is consistent with the original hypothesis H1b. Price perception has a direct positive and significant impact on willingness to use, which is consistent with the hypothesis H1c, while service quality perception and willingness to use have no significant impact, assuming that H1d is not supported.

Table 3.Hypothesis Testing

\begin{tabular}{lccc}
\hline Hypothesis & Standardized Coefficient & P-value & Result \\
\hline H1a: FV-->BI & $\mathbf{0 . 1 5 9}$ & $\mathbf{0 . 0 1 2}$ & Support \\
H1b: EV-->BI & $\mathbf{0 . 3 7 2}$ & $* * *$ & Support \\
H1c: PPV-->BI & $\mathbf{0 . 3 8 0}$ & $* * *$ & Support \\
H1d: SQ-->BI & 0.047 & 0.491 & Not Support \\
\hline
\end{tabular}

Note: $* * *$ indicates $\mathrm{P}<0.01$

\subsection{Moderating Effect Testing}

As can be seen from the original hypothesis and Figure 1, the impact of customer perception on willingness to use is moderated by green value. The moderating effect of green value is verified by the significance of the interaction between green value and customer perception factors (Table 4). Therefore, this paper uses hierarchical regression analysis to verify the regulatory role of green value and commodity value. Because of the need to verify the interaction between regulatory variables and independent variables, in order to reduce the multiple collinearity among variables in the regression equation, all variables were centralized before the analysis.

In order to analyze the moderating effect of green value, the interactive variables of green value and perception factors are added into the model. The results show that the functional value and price perception follow the change of green value, but have different effects on the use intention. Therefore, $\mathrm{H} 2 \mathrm{a}$ and $\mathrm{H} 2 \mathrm{c}$ are supported by data structure. In other words, the higher the customer perceives the green value of the shared logistics facilities, the higher their willingness to use them.

Table 4. Moderating Effect Testing

\begin{tabular}{|c|c|c|c|}
\hline \multicolumn{2}{|c|}{ Variables } & Standardized regression coefficient & T-value \\
\hline \multirow{4}{*}{ independent variable } & FV & 0.61 & $4.30 * * *$ \\
\hline & EV & 0.56 & $4.75 * * *$ \\
\hline & PPV & 0.83 & $6.41 * * *$ \\
\hline & SQ & 0.48 & $3.64 * * *$ \\
\hline \multirow{4}{*}{ Interaction Items } & GV*FV & -0.45 & $-2.04 *$ \\
\hline & $\mathrm{GV} * \mathrm{EV}$ & -0.08 & -0.43 \\
\hline & GV*PPV & -0.47 & $-2.71 *$ \\
\hline & $\mathrm{GV}^{*} \mathrm{SQ}$ & -0.21 & -0.99 \\
\hline
\end{tabular}

Note: $* \mathrm{P}<0.05, * * * \mathrm{P}<0.001$, dependent variable: use intention

\section{Conclusion}

Through questionnaires, this paper studies the impact of perception factors on consumers'willingness to use smart express cabinets in the context of shared economy. After analyzing the reliability and validity of 404 valid questionnaires collected, the hypothesis test was carried out by using structural equation model and regression analysis. The results showed that consumers'perception of the functional value, emotional value and price of the shared intelligent express cabinet directly affected their willingness to use it. In addition, this paper finds that green value regulates the impact of functional value and price perception on willingness to use.

First of all, this paper is an earlier research on the factors affecting the willingness to use smart express cabinets under the background of shared economy. Previous research on willingness to use smart express cabinets focused on traditional business models, and the object of study in the logistics field is mostly for the logistics 
industry or express companies. This paper expands the research field and object of willingness to use smart express cabinets. Secondly, based on the characteristics of shared economy, this paper finds that green value can regulate the relationship between some perceptive factors and behavioral intention. Previous studies mostly emphasize the positive role of green value, but seldom study the regulatory role of green value. This discovery is of great significance to the study of perceptual value theory and product behavioral intention theory. This paper takes the intelligent express cabinet as the empirical research object of shared logistics service facilities, combines the perception factor theory with the actual products of shared logistics, and points out the direction for future research.

The conclusion of this paper has important enlightenment significance for logistics enterprise management. Firstly, functional value, emotional value and price perception have a significant positive impact on the willingness to use. Therefore, logistics enterprises participating in the construction and operation of shared logistics facilities should ensure the quality of shared logistics facilities, create a good relationship between shared logistics facilities and customers, attach importance to consumers'emotional experience, and establish a sound charging system. Secondly, green value will affect customers'willingness to use. Logistics enterprises should actively assume social responsibility, strengthen the corporate image of green environmental protection, vigorously develop, promote and apply energy-saving and environmental protection materials, and promote the recycling and reuse of resources. This is the source of sustainable competitiveness of enterprises, and also an important means to enhance customer perceived value.

\section{References}

Ariffina S, Yusofa J M, Putita L, et al. Factors Influencing Per-ceived Quality and Repurchase Intention towards Green Products [J]. Procedia Economics and Finance, 2016( 1) : 391-396.

Chang T Z, Wildt A R. Price, product information, and purchase intention: An empirical study [J]. Journal of the Academy of Marketing Science, 1994, 22(1):16-27.

Chen C F. Investigating structural relationships between service quality, perceived value, satisfaction, and behavioral intentions for air passengers: Evidence from Taiwan[J]. Transportation Research Part A, 2008, 42(4):709-717.

Dodds W B, Monroe K B, Grewal D. Effects of Price, Brand, and Store Information on Buyers' Product Evaluations[J]. Journal of Marketing Research, 1991, 28(3):307-319.

Eggert A, Ulaga W. Customer perceived value: a substitute for satisfaction in business markets? [J]. Journal of Business \& Industrial Marketing, 2013, 17(2/3):107-118.

Fishbein, M.; Manfredo , M.J..A Theory of Behavior Change in Influencing Human Behavior: Theory and Applications in Recreation, Tourism and Nature Resources Management, M. J Manfredo,Ed,1992:29-50. 